\title{
Academic Career Award
}

National Cancer Institute

\section{Source}

National Cancer Institute. Academic Career Award. NCI Thesaurus. Code C18613.

To create and encourage a stimulating approach to disease curricula that will attract high-quality students, foster academic career development of promising young teacherinvestigators, develop and implement excellent multidisciplinary curricula through interchange of ideas, and enable the grantee institution to streng then its existing teaching program. (Grant Guidelines and Descriptions, $\mathrm{NCl}$ ) 